\title{
PERANCANGAN DISPLAY VISUAL KUANTITATIF PADA SISTEM MANUSIA MESIN
}

\author{
Mujahidin ${ }^{1}$
}

ABSTRACT

Work system consist of man and machine system, human senses need a tool to respons all kind of stimulus such an information given by machine or outside of system, so that human can control machine well. It means that we need display design based on the characteristic of human senses ability in catching information

There are many kind of display that can be made depend with information characteristics. This research will give quantitative visual display design fixed to information characteristics given and also consider with human visual ability accepting an information from outside.

\section{Key Words : Information, Display, Visual, Kuantitatif}

\section{PENDAHULUAN}

Manusia dalam melakukan aktivitasnya tidak akan pernah lepas dari penggunaan alat bantu (physical components) yang dipakai dalam mempermudah dalam mencapai tujuannya. Alat bantu yang digunakan tersebut bermacam-macam jenisnya tergantung dari kebutuhan dan kekomplekan kerja yang dilakukan. Alat bantu tersebut bisa berupa obyek fisik, peralatan bantu, mesin, fasilitas produksi dan lain-lain.

Hubungan antara manusia dengan komponen fisik membentuk suatu interaksi yang secara bersama-sama membentuk suatu sistem yang disebut sebagai manusia mesin (man machine system).

Sistem manusia-mesin adalah kombinasi antara satu atau lebih manusia dengan satu atau lebih komponen fisik yang saling berinteraksi dengan arus input dan output yang dihasilkan. Gambar 1 memberikan ilustrasi arus informasi yang terjadi pada sistem yang terdiri dari dua subsistem, yaitu tubuh manusia (human being) dan mesin.

\section{TINJAUAN PUSTAKA}

\section{Sistem Manusia-Mesin}

Pada sistem manusia-mesin, seperti terlihat pada gambar 1, manusia menerima rangsangan (distal stimuli) dengan berbagai macam jenis. Rangsangan tersebut tidak semuanya dapat diterima langsung oleh indra manusia dalam bentuk energi (proximal stimuli), misalnya suara, cahaya, energi panas, tetapi sebagian harus menggunakan alat bantu berupa display yang bisa mempresentasikan rangsangan dengan satuan nilai tertentu. Proses 
penangkapan rangsangan dari distla stimuli menjadi proximal stimuli, yang sebagian membutuhkan alat pengindra buatan dapat dilihat pada gambar 2 .

$$
\text { Terdapat berbagai macam display }
$$

tergantung pada bagian indra mana rangsangan berupa energi tersebut ditangkap oleh indra manusia, yaitu display visual, display auditry, display taktual dan display olfactory.

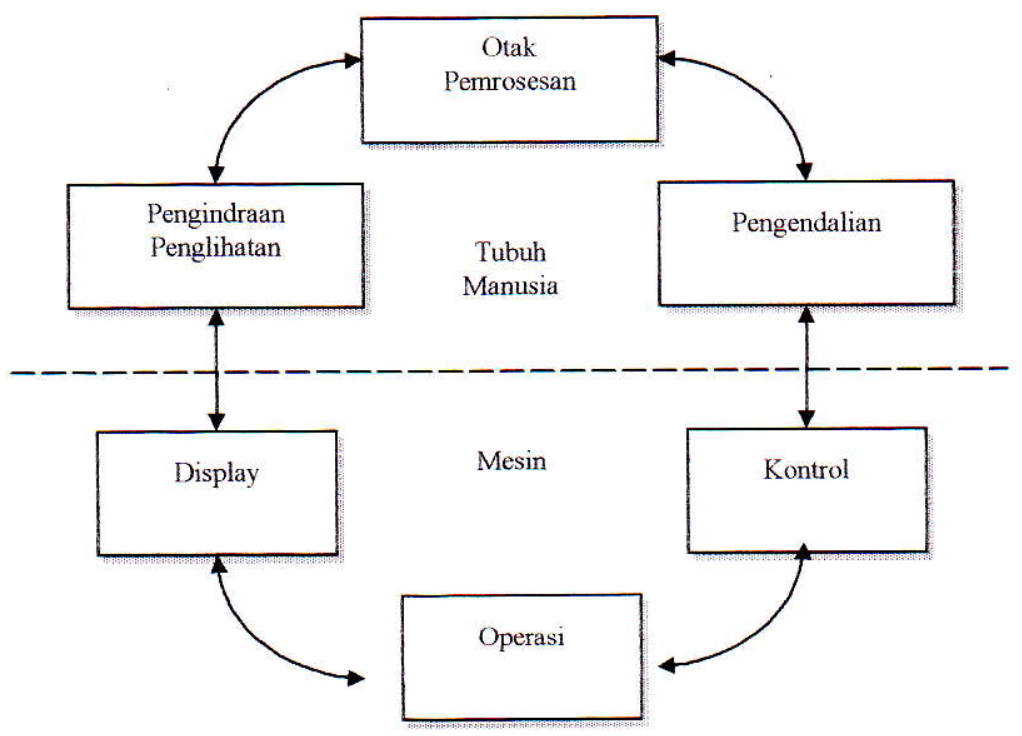

Gambar 1

Sistem Manusia Mesin

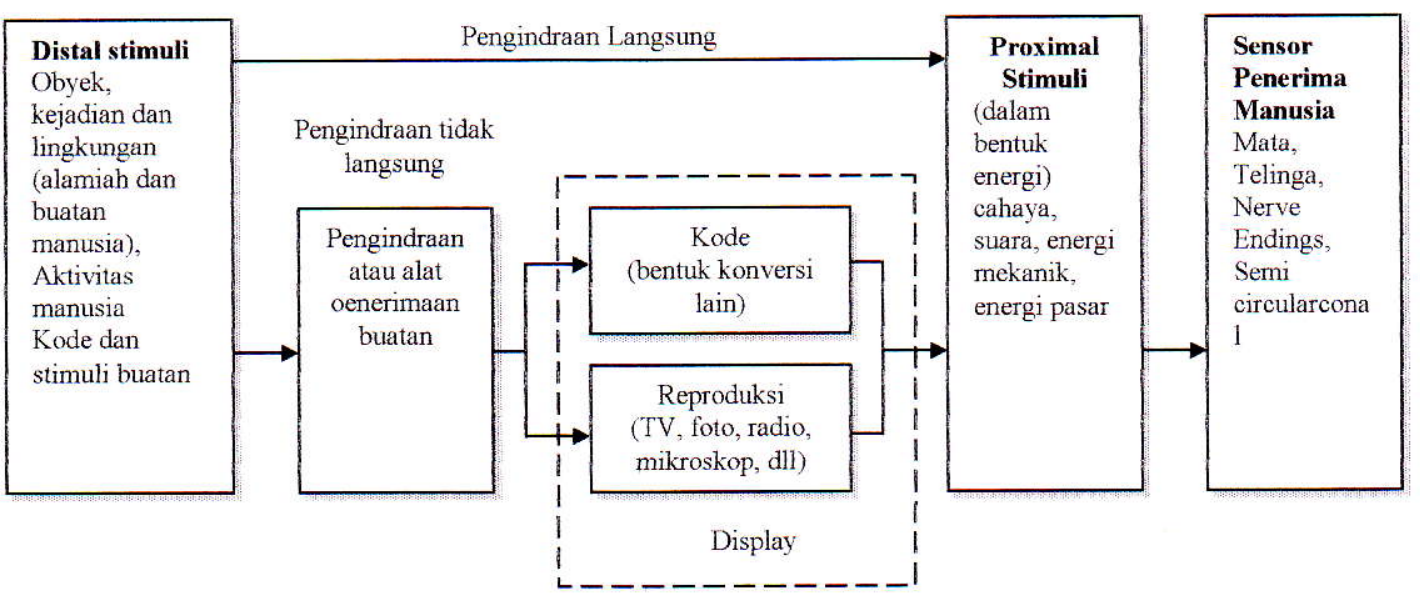

\section{Gambar 2}

Skema aliran informasi berasal dari sumber (stimuli) 


\section{Display}

Display pada sistem manusia-mesin digunakan untuk mempresentasikan informasi yang diberikan oleh mesin mengenai kondisi operasi kerja yang sedang atau telah berjalan. Mislanya speed meter, fuel display, layar monitor dan lain-lain. Display juga digunakan untuk mempresentasikan mengenai kondisi lingkungan, misalnya suhu udara, tekanan udara, kodisi cuaca dan sebagainya. Ada juga display yang sifatnya statis, yaitu memberikan informasi berupa gambar atau tulisan yang tidak berubah. Dalam hal ini misalnya rambu-rambu lalu lintas, peta lokasi, grafik, dan masih banyak lagi yang dapat kita temui dalam lingkungan seharihari yang dapat diambil contoh debagai display. Gambar 3 menunjukkan salah satu tipe display yang informasinya ditangkap oleh indra penglihatan manusia, yaitu display visual yang secara garis besar dibagi atas display statik dan display dinamik beserta contohnya.

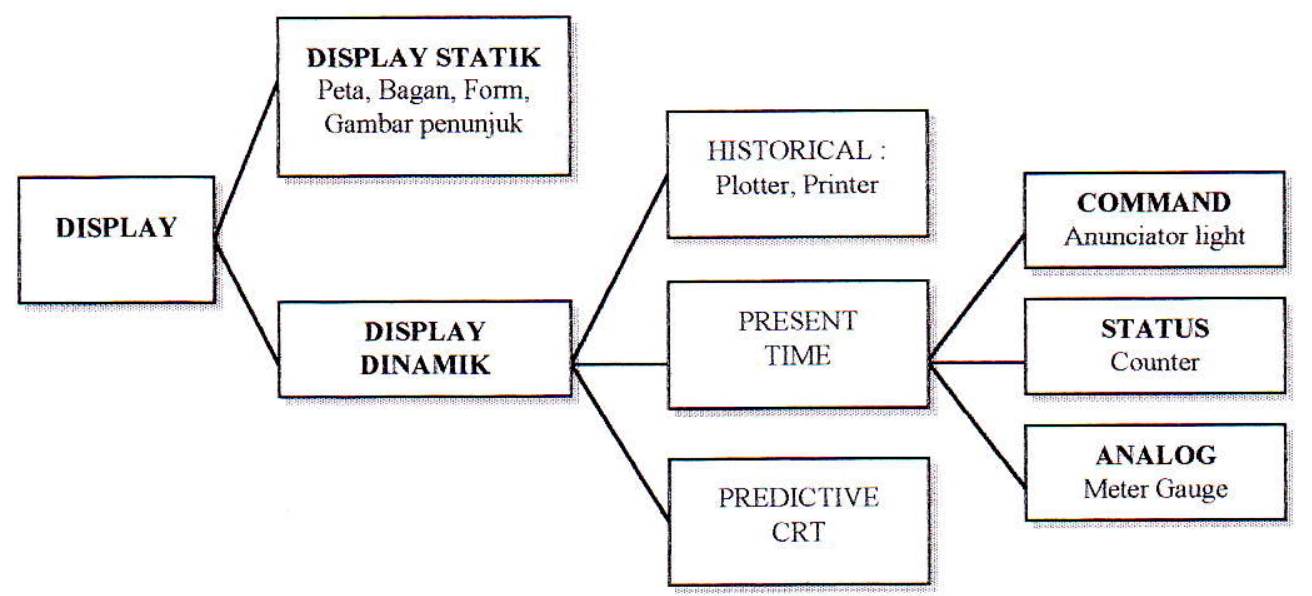

Gambar 3
Tipe display visual

\section{Display Visual Kuantitatif}

Indra manusia dalam menerima informasi yang diberikan oleh mesin membutuhkan tampilan yang dapat diterima oleh indra penglihatan sehingga manusia dapat memahami kondisi dan mengoperasikan mesin dengan tepat. Misalnya seorang operator dalam mengoperasikan sebuah boiler, maka ia harus mengetahui tekanan udara yang terjadi sehingga ia dapat menentukan jumlah air yang harus diberikan. Contoh lain misalkan seseorang yang sedang bepergian mengendarai mobil ke luar kota, supaya tahu arah tujuan yang benar dan tidak terjadi kecelakaan, maka ia harus membaca setiap rambu (statis display) di sepanjang jalan yang ditempuh, dan untuk mengetahui keadaan kendaraan, ia selalu melihat display yang terletak di kendaraannya. Atau seorang petugas yang bekerja pada ruang pengaturan lalu lintas udara, maka ia akan berhadapan dengan berbagai macam display sehingga 
dapat mengawasi kondisi cuaca dan perjalanan pesawat terbang.

Pada makalah ini secara khusus akan dijelasakan mengenai rancangan display visual kuantitatif, yang merupakan salah satu jenis display yang paling banyak digunakan dalam sistem manusia-mesin. Pada dasarnya dalam merancang display terdapat tiga hal pokok yang harus dipertimbangkan (Sumber : Sanders dan Ernest, 1987, hal. 85), yaitu :

1. Visibility aspect, yaitu mengenai kualitas dari karakter atau simbol yang diberikan harus dapat dibedakan dengan kondisi sekeliling. Dalam hal ini disebut juga detectibility aspect.
2. Legibility aspect, yaitu ciri-ciri karakter atau simbol dapat dibedakan satu sama linnya. Dalam hal ini akan tergantung dari desain dan bentuk huruf, tanda skala, kontras dan pencahayaan.

3. Readibility aspect, yaitu kemampuan karakter atau simbol untuk dapat dibaca dengan

tepat.

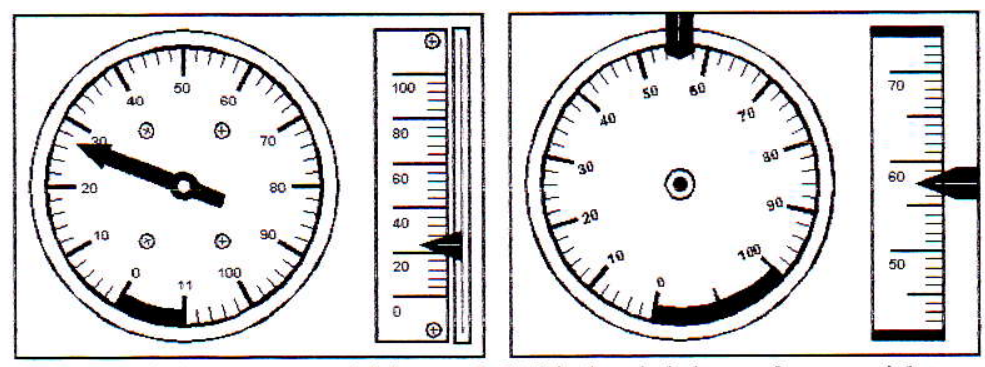

a) Display skala tetap - penunjuk bergerak b) Display skala bergerak - penunjuk tetap

\section{$9 \longdiv { 5 } \longdiv { 1 1 4 8 }$}

c) Display konter

\section{Gambar 4 \\ Tipe kuantitatif display visual}

Tujuan dari display visual kuantitatif seperti pada gambar 4 adalah menyediakan informasi nilai-nilai kuantitatif dari beberapa variabel yang berubah-ubah. Secara konvensional display visual kuantitatif dibagi ke dalam tiga kelompok :

1. Skala tetap-penunjuk bergerak

2. Skala bergerak-penunjuk tetap
3. Counter

Dari ketiga tipe display visual kuantitatif di atas, masing-masing mempunyai kegunaan yang berbeda-beda tergantung dari jenis informasi yang diberikan. Tabel 1 memberikan karakteristik display visual kuantitatif dalam memberikan informasi. 


\section{METODOLOGI PENELITIAN}

Dalam perancangan ini data-data

yang diperlukan antata lain adalah

a. Distal stimuli

Proximal Stimuli

Sensor Penerima Manusia

HASIL DAN PEMBAHASAN

Tabel 1

Karakteristik Display Visual Kuantitatif

\begin{tabular}{|l|c|c|c|}
\cline { 2 - 4 } & Counter & $\begin{array}{c}\text { Skala bergerak } \\
\text { Penunjuk tetap }\end{array}$ & $\begin{array}{c}\text { Skala tetap } \\
\text { Penunjuk bergerak }\end{array}$ \\
\hline Informasi kuantitatif & Baik & Cukup & Cukup \\
\hline Informasi kualitatis & Kurang & Baik & Cukup \\
\hline Pencahayaan kurang & Baik & Kurang & Cukup \\
\hline Pengecekan & Cukup & Baik & Baik \\
\hline Perbedaan dari sebuah nilai & Kurang & kurang \\
\hline
\end{tabular}

\section{Disain Display Visual Kuantitatif}
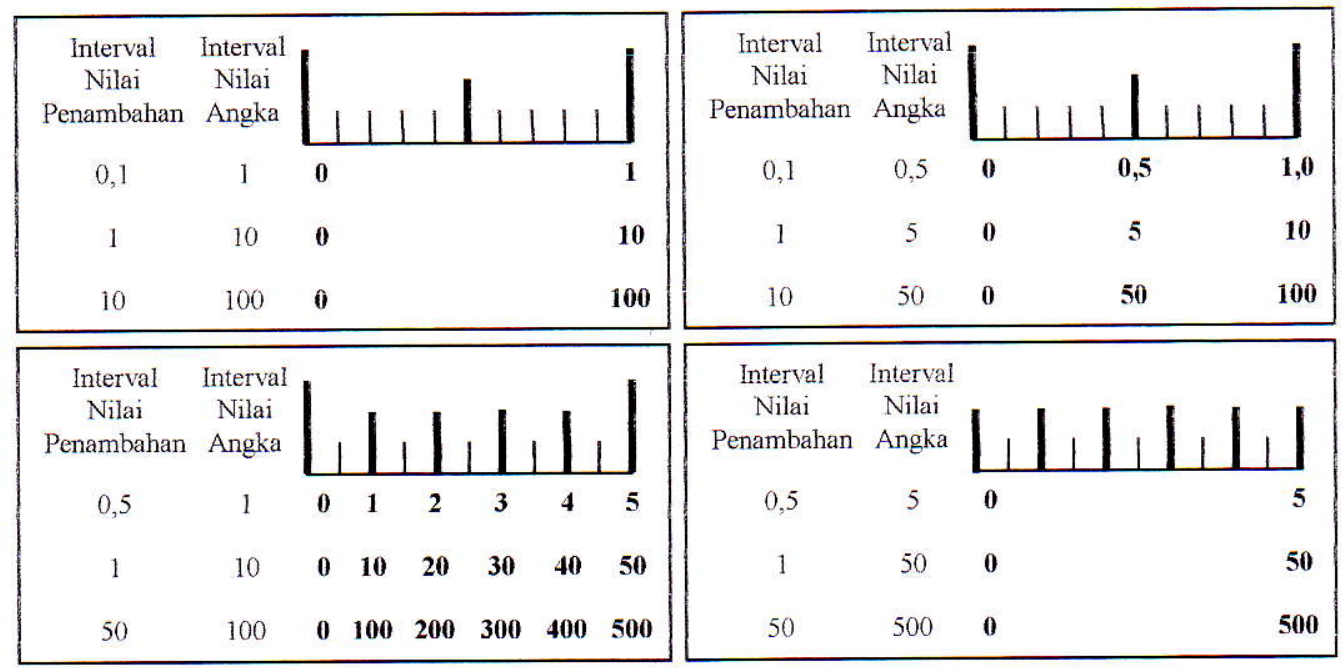

\section{Gambar 5}

Contoh progres angka pada display Visual Kuantitatif

Dalam merancang display visual kuantitatif ciri-ciri spesifik harus ditetapkan secara standar sehingga rancangan display b. display visual

kuantitatif display visual 
dijelaskan sebelumnya. Ciri-ciri tersebut adalah :

1. Progres karakter angka, menurut Whitehurst (1982), urutan karakter angka pada display sebaiknya mempunyai interval persatuan, perlimaan, persepuluhan atau perseratusan. Misalnya angka pada display adalah $0,1,2,3,4,5$ dan seterusnya, atau $0,10,20,30,40$ dan seterusnya. Pada hal ini dihinari interval angka yang desimal. Untuk interval angka perseribuan, persatujutaan atau perseperseribuan biasanya menggunakan satuan kilo (k), mega (mg) atau mili $(\mathrm{ml})$ serta satuan lain yang sesuai sehingga mudah dibaca.

2. Jarum Penunjuk (pointer), menurut Whitehurst (1982), dalam mendisain poiter hal yang penting adalah jarak antara ujung pointer dan permukaan skala harus seminimal mungkin tidak boleh bertumpukan, dan arah penunjukan pointer harus sejajar dengan skala.

3. Tanda skala (scale marker), dalam penentuan ukuran tanda skala tidak boleh terlalu besar sehingga display kelihatan penuh sesak, ataupun terlalu kecil sehingga sulit dibaca. Menurut Whitehurst (1982) ukuran tanda skala terbagi menjadi tiga, yaitu tanda skala utama (major scale marker), tanda skala tengah (intermediate scale marker) dan tanda skala kecil (minor scale marker). Ukuran tersebut untuk jarak pandang 71 $\mathrm{cm}$ (28 in) dengan kondisi penerangan normal (normal illumination). Untuk jarak pandang yang lain harus disesuaikan dengan perbandingan.

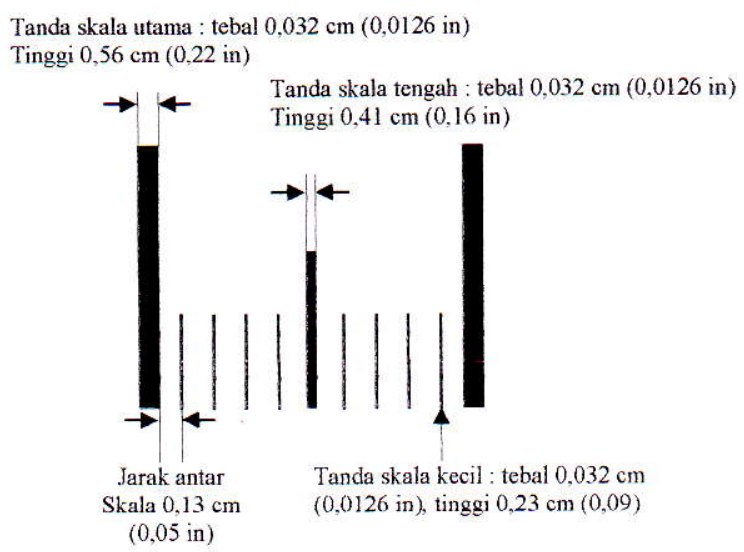

\section{Gambar 6 \\ Petunjuk perancangan tanda skala pada Kuantitatif display visual}

4. Bentuk alfanumetrik, ayitu karakter huruf atau angka pada display menurut Peter dan Adams (1959) didisain dengan mempertimbangkan keefektifan dengan tanpa mengurangi kemampuan readibility. Untuk itu terdapat ketentuan seperti berikut : 
a. Tinggi karakter, tinggi karakter dihubungkan dengan beberapa variabel, yaitu :

$$
\begin{array}{ll}
\mathrm{H}(\mathrm{cm}) & =0,000866 \mathrm{D}+\mathrm{K}_{1}+\mathrm{K}_{2} \\
\text { atau } & \\
\mathrm{H}(\mathrm{in}) & =0,0022 \mathrm{D}+\mathrm{K}_{1}+\mathrm{K}_{2} \\
\text { Dimana : } & \\
\mathrm{H} & : \text { tinggi karakter } \\
\mathrm{D} & : \text { jarak pandang }(\mathrm{cm} \text { atau }
\end{array}
$$

in)

$\mathrm{K}_{1}$ :

faktor koreksi untuk penerangan dan kondisi penglihatan. $\mathrm{K}_{1}=0,15 \mathrm{~cm}(0,06 \mathrm{in})$ untuk di atas $1,0 \mathrm{fc}$ pada kondisi pencahayaan yang kurang (unfavourable reading), $\mathrm{K}_{1}=$ $0,4 \mathrm{~cm}(0,16 \mathrm{in})$ untuk di atas $1,0 \mathrm{fc}$ pada kondisi pencahayaan yang kurang baik atau di bawah 1,0 fc pada kondisi pencahayaan baik. $\mathrm{K}_{1}=0,66$ $\mathrm{cm}(0,26 \mathrm{in})$ untuk di bawah $1,0 \mathrm{fc}$ pada kondisi pencahayaan kurang baik.
$\mathrm{K}_{2}$ yang ditampilkan pada display. $\mathrm{K}_{2}=0$ bila tanda yang ditampilkan adalah tidak penting (nonimportant marking) dan $\mathrm{K}_{2}$ $=0,19 \mathrm{~cm}(0,06 \mathrm{in})$, bila karakter yang ditampilkan adalah penting (important marking).

b. Posisi karakter, posisi karater huruf maupun angka pada posisi tegak lurus.

c. Rasio lebar dan tinggi karakter (character width / height ratio), menurut Heglin (1973), rasio lebar dan tinggi untuk angka numerik merekomendasikan 3 : 5, dan perbandingan untuk huruf kapital adalah $1: 1$ sampai $3: 5$.

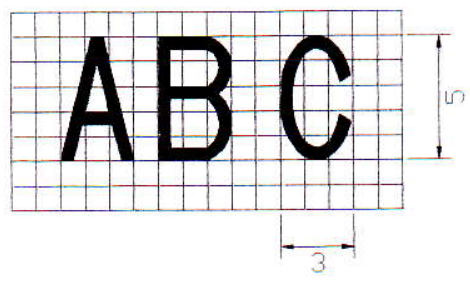

Gambar 7

Ilustrasi rasio lebar dan tinggi $3: 5$

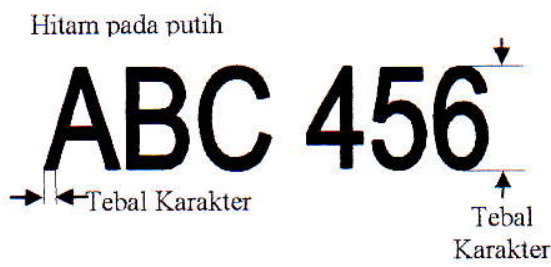

Hitam pada putih

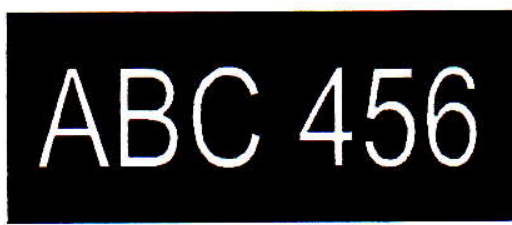

Gambar 8

Ilustrasi rasio tebal dan tinggi karakter 
d. Rasio tebal dan tinggi karakter (stroke width height ratio), menurut Berger (1994) rasio ketebalan batang dan tinggi adalah 1: 6 sampai 1: 8 untuk karakter warna hitam pada dasar putih, dan 1: 8 sampai 1: 10 untuk karakter warma putih pada dasar hitam.

e. Tipe karakter, terdapat lebih dari 30.000 tipe karakter yang dapat digunakan dalam penulisan huruf atau angka numerik yang kesemuanya terbagi dalam tiga kelompok, yaitu : pertama, Roman, kelompok ini yang paling sering digunakan. Kedua San Sarif, kelompok ini biasanya digunakan untuk penulisan judul. Ketiga Black Letter, kelompok ini biasanya digunakan pada huruf dan angka pada display.

\section{KESIMPULAN}

Dari uraian di atas dapatlah disimpulkan bahwa dalam merancang sebuah display hendaknya dilakukan pertimbangan ciri-ciri karakteristik yang tepat, sehingga display yang dibuat dapat mempresentasikan informasi dengan baik kepada manusia.

\section{DAFTAR PUSTAKA}

Berger, C, 1944, I, Stroke-Width, Form and Horisontal Spacing on Numeral as Determinant of The Threshold of Recognition, Journal of Applaid Psychology, 28 hal 208-231, pada Pulat, B Mustafa, 1992, Fundamentals of Industrial Ergonomics, Prentice Hall, Englewood Cliffs, New Jersey.

Berger, C, 1944, I, Stroke-Width, Form and

Horisontal Spacing on Numeral as

Determinant of The Threshold of Recognition, Journal of Applaid Psychology, 28 hal 336-340, pada Pulat, B Mustafa, 1992, Fundamentals of Industrial Ergonomics, Prentice Hall, Englewood Cliffs, New Jersey.

Grether, W, F and Baker, C.A., 1973, Visual Presentation of Information, pada $\mathrm{H}$. A. Van Cott and R. G. Kinkade, Human Engineering Guide to Equipment Design (rev. ed). Washington : Government Printing Office pada Sanders, Mark S. and Ernest J. McCornick, 1987, Human Factor Engineering and Design, McGraw Hill.

Heglin, H. J, 1973, NAVSHIPS Display Illumination Design Guide : 11 Human Factors (NELC/TD223), Naval Electronocs Laboratory Center, San Diego 
Peters G, dan Adams, B. B., 1959, These Three Criteria for Readable Panel Markings, Product Engineering, 30 (21), hal 55-57 pada Pulat, B. Mustafa, 1992, Fundamentals of Industrial Ergonomics, Prentice Hall, Englewood Cliffs, New Jersey.

Pulat B. Mustafa, 1992, Fundamentals of Industrial Ergonomics, Prentice Hall.

Sanders, Mark S dan Ernest J. McCornick, 1987, Human Factor Engineering and Design, Mc-Graw Hil International.

Whitehurst, H. O., 1982, Screening Design Used to Estimate The Relative Effects to Display Factor on dial Reading. Human Factors, 24 (3), 301-310, pada Sanders, Mark S and Ernest J McCornick, 1987, Human Factor Engineering and Design, McGraw Hill International. 